\title{
Regulação jurídica brasileira das férias laborais
}

\author{
Brazilian legal regulation of labour vacations
}

\author{
Alex SANDRo TAVARES DA Silva ${ }^{a}$ \\ LÉo SiMÕES dos SANTOS PILAU ${ }^{b}$
}

\begin{abstract}
RESUMO
O presente artigo aborda o tema das férias laborais no que diz respeito a sua definição conceitual, natureza jurídica, pressupostos legais, jurisprudência do Tribunal Superior do Trabalho (TST), do Supremo Tribunal Federal (STF) e convenções da Organização Internacional do Trabalho (OIT). Ao final conclui-se que as férias têm um caráter de cuidado com a saúde, é direito irrenunciável, constitucional, legal e remuneráveis com o adicional mínimo de $1 / 3$, sem exceção.
\end{abstract}

Palavras-chave: Férias. Direito do Trabalho. Jurisprudência.

\begin{abstract}
This article addresses the issue of labor vacation with regard to its conceptual definition, juridical nature, legal requirements, jurisprudence of the Tribunal Superior do Trabalho (TST), Supremo Tribunal Federal (STF) and conventions of the International Labour Organization (ILO). At the end it is concluded that the vacation have a character of health care, an indispensable, constitutional, legal and remunerable with minimal additional third without exception right.
\end{abstract}

Keywords: Vacations. Labor Law. Jurisprudence.

\section{INTRODUÇÃO}

Inicialmente, antes de analisarmos focalmente o tema das férias, apresenta-se profícuo destacar um breve histórico acerca do princípio da proteção, norteador do Direito do Trabalho. Este princípio remete seu desenvolvimento a uma sucessão de fatos importantes para construção da ciência jurídica laboral. Utilizandose da Revolução Industrial como ponto de partida, pode-se aduzir que os direitos dos trabalhadores, neste primeiro momento, eram inexistentes. A demanda de mão de obra era consideravelmente menor do que a procura pelo trabalho, ocasionando situações de extrema desconsideração do indivíduo como ser humano, sendo este utilizado como uma engrenagem, uma peça necessária para o desenvolvimento da indústria, descartável quando não mais útil para produção.

Em virtude do advento do tear mecânico e da máquina a vapor, iniciou-se a modernização das técnicas de produção econômica e, como consequência lógica, a substituição da mão de obra pelas máquinas ${ }^{1}$. Em virtude da máquina funcionar incessantemente, apresentava-se conveniente para aqueles poucos que detinham o poder econômico nas mãos, que os trabalhadores "funcionassem" da mesma maneira. Referida circunstância somada com o fato da massa de miseráveis e desempregados que surgia na Europa, preocupava os indivíduos, levando estes a se submeterem a jornadas extremamente longas, de quinze horas ou mais, ambientes de trabalho fechados, insalubres, mal iluminados e sem segurança ${ }^{2}$.

Contudo, a aglomeração dos trabalhadores em torno das unidades de produção facilitou a sua intercomunicação e despertou nestes uma "consciência de classe" 3 . Diante desta situação, ocorreu que, em um segundo momento, os trabalhadores perceberam a força que exerciam não de maneira individual, mas coletivamente. Força esta que foi demonstrada nos

\footnotetext{
a Advogado. Bacharel em Direito (PUCRS). Graduado em Psicologia (UNISINOS). Mestre em Psicologia Social e Análise Institucional (UFRGS). Criador e tutor do curso de Psicologia Forense (Portal Educação).<alextavares@gmail.com>.

b Advogado. Bacharel em Direito (PUCRS). Especializando em Direito do Trabalho e Processo do Trabalho (PUCRS). <leossp@outlook.com>.
} 
enfrentamentos com a classe patronal por melhores condições de trabalho, fazendo surgir as primeiras normas de Direito do Trabalho, materializadas nos contratos coletivos de trabalho, negociadas com os detentores do capital, ou até mesmo nas leis fixadas pelo Estado, que temia uma convulsão social e a perda do seu poder ${ }^{4}$.

Repara-se que o Direito do Trabalho nasceu localizado em meio a uma relação desigual, onde restava de forma transparente a necessidade de proteção do hipossuficiente por meio da norma trabalhista. A natureza protetiva da norma trabalhista existe como um reflexo do Direito do Trabalho desde a sua origem, justificando o caráter desse ramo do Direito e o surgimento do princípio da proteção ${ }^{5}$.

Dos primórdios do Direito do Trabalho até a sua posterior constitucionalização, nota-se uma preocupação com as condições de labor do trabalhador e as implicações ocasionadas em sua saúde e dignidade. Hodiernamente, no Brasil, pode-se afirmar que existe uma preocupação por parte do Estado em garantir, proteger, as condições saudáveis de trabalho. A base desta afirmação encontra-se demonstrada, principalmente, no artigo $7^{\circ}$ da Constituição Federal, que assegura, de forma exemplificativa ${ }^{6}$, inúmeros direitos dos trabalhadores urbanos e rurais.

Destaca-se estar inserido o $\operatorname{artigo~}^{\circ} \stackrel{0}{ }$ da Constituição Federal, no Título II, Dos Direitos e Garantias Fundamentais, Capítulo II, Dos Direitos Sociais. Os direitos sociais são reconhecidos como direitos fundamentais do homem, caracterizando-se como verdadeiras liberdades positivas ${ }^{7}$. Ademais, possuem caráter de normas de ordem pública, com a característica de imperativas, invioláveis, portanto, pela vontade das partes integrantes da relação de trabalho ${ }^{8}$.

Dentre estas normas de ordem pública, consideradas verdadeiro reflexo do princípio da proteção, podese destacar o artigo 7º , inciso XVII, da Constituição Federal, que prevê o direito ao gozo de férias anuais remuneradas com, pelo menos, um terço a mais do que o salário normal. Giza-se que o referido instituto das férias, amparo legal irrenunciável para que o indivíduo possa recuperar sua energia dispendida no trabalho, será o objeto central do presente estudo, sendo examinado quanto a sua definição, natureza jurídica e jurisprudências pertinentes.

\section{DEFINIÇÃO E NATUREZA JURÍDICA DAS FÉRIAS}

Férias, do latim "feria" (dias feriales), para os romanos era literalmente dia de festas. Ela é a espécie de descanso legal mais longo do trabalhador. Outros descansos legais são o intervalo intrajornada (de 15 minutos até 2 horas - art. 71 da CLT), o intervalo interjornada (de 11 horas - artigo 66 da CLT) e o repouso semanal remunerado (24 horas consecutivas - art.7을 XIII da CF/1988) ${ }^{9}$.

Férias é número de dias sem trabalho, anual e remunerado em que o trabalhador que cumpriu determinadas condições interrompe o seu trabalho ${ }^{10}$, sem prejuízo da sua remuneração ${ }^{11}$. Em outras palavras, é um dos direitos do empregado interromper o seu trabalho por iniciativa do empregador, por período variável anual, sem perda da remuneração, desde que cumpridas certas condições de tempo no ano anterior, a fim de atender aos deveres de restauração orgânica e social ${ }^{12}$.

As férias são uns dos elementos básicos para se conquistar condições justas, equitativas e satisfatórias de trabalho ${ }^{13}$. Não são prêmio nem vantagem, são direito de lazer, descanso e ócio. Espécie de direito irrenunciável, pois buscam assegurar a saúde física e mental. Seu exercício pode ter reflexos no aspecto social (ex.: contato interpessoal); econômico (remuneração e adicional sem trabalho); turístico (ex.: tempo para viajar) ${ }^{14}$.

Desse modo, entende-se que as férias, entre outras funções, também apresentam uma dimensão de cuidado à saúde do trabalhador, um período de descanso remunerado com a possibilidade de envolvimento em atividades de lazer, familiares, conjugais, amizades. Trata-se de direito irrenunciável do empregado, possuindo caráter eminentemente higiênico. Estudos na área da medicina do trabalho demonstram que a ausência da fruição das férias, gozadas em momento oportuno, geram prejuízos ao organismo do trabalhador, que encontra-se exposto a uma período demasiadamente extenso de trabalho ${ }^{15}$.

Do ponto de vista histórico, a Inglaterra, em 1872, foi o primeiro país a promulgar uma lei sobre férias com o objetivo de resguardar direitos aos operários das indústrias. No caso do Brasil, o país foi o segundo a conceder o direito de férias anuais remuneradas e o sexto a estender o direito a todos os empregados e operários de empresas privadas (Lei 4.582/1925) ${ }^{16}$.

A natureza jurídica das férias é dupla ${ }^{17}$. Do ponto de vista do empregador é obrigação de fazer (consentir no afastamento) e de dar (pagar o salário equivalente do empregado). Pelo viés do empregado é um direito de exigir obrigações do empregador e de se abster de trabalhar durante as férias. Nesse sentido, ao direito do empregado de gozar o descanso anual corresponde a obrigação do empregador de não fazer (deixar de exigir serviços). Assim, férias é direito do trabalhador de não prestar os serviços contratados; a obrigação do empregador é não exigir serviços ${ }^{18}$. 
Na Constituição Federal de 1988 é expresso o direito de férias do empregado. No seu art.7º, XVII, consta o "gozo de férias anuais remuneradas com, pelo menos, um terço a mais do que o salário normal". Neste dispositivo está a "estrutura tríplice" das férias e os seus três princípios; o princípio da fruição (obrigação de não fazer: descanso e recuperação); o princípio da anualidade (periodicidade) e o princípio da sobrerremuneração (acréscimo de um terço da sua remuneração normal) ${ }^{19}$.

As férias, conforme ordenamento jurídico brasileiro, classificam-se quanto ${ }^{20}$ :

- ao número de empregados - em individuais e coletivas;

- ao vencimento do período aquisitivo - em férias vencidas e proporcionais;

- à duração - em férias de 0 até 30 dias;

- à remuneração - em simples ou em dobro (concedidas ou pagas fora do período legal);

- à utilização - em integral e fracionada (dividida em mais de um período, um dos quais não poderá ser inferior a 10 dias);

- ao regime jurídico - em geral, aplicável a todo empregado, e especial, aplicável a uma categoria (ex.: OIT, Convenção 146: férias dos marítimos);

- ao direito de ação - em férias prescritas (reclamadas após o prazo de 5 anos a partir do fim do período aquisitivo) e não prescritas (reclamadas no prazo de 5 anos).

\section{JURISPRUDÊNCIA DO TST}

SUM-7 FÉRIAS (mantida) - Res. 121/2003, DJ 19, 20 e 21.11.2003.

A indenização pelo não-deferimento das férias no tempo oportuno será calculada com base na remuneração devida ao empregado na época da reclamação ou, se for o caso, na da extinção do contrato.

Nessa Súmula, o TST expressa o entendimento da existência do direito do trabalhador receber o valor das férias indenizadas pelo salário da época da sua reclamação trabalhista, no caso de demanda judicial ter sido proposta durante a execução do contrato laboral ou pela remuneração devida quando da extinção do pacto laboral.

O posicionamento do Tribunal decorre da interpretação da disposição contida no art. 142 da CLT: o empregado perceberá, durante as férias, a remuneração que lhe for devida na data da sua concessão.

Assim, a Súmula 7 do TST difere remuneração da época da reclamação e remuneração da extinção do contrato. A diferença dá-se pela viabilidade de se ajuizar demanda pleiteando pagamento das férias em dobro durante o contrato de trabalho (fixação por sentença - situação rara pelo medo de retaliações do empregador) ou depois do término do contrato. $\mathrm{Na}$ primeira situação (queixa durante contrato), o salário de indenização é o da data do ajuizamento. Na segunda (queixa após contrato), considera-se o último salário (época da rescisão contratual) $^{21}$.

SUM-10 PROFESSOR. DISPENSA SEM JUSTA CAUSA. TÉRMINO DO ANO LETIVO OU NO CURSO DE FÉRIAS ESCOLARES. AVISO PRÉVIO (redação alterada em sessão do Tribunal Pleno realizada em 14.09.2012) Res. 185/2012 - DEJT divulgado em 25, 26 e 27.09.2012.

$O$ direito aos salários do periodo de férias escolares assegurado aos professores (art. 322, caput e $\xi 3^{\circ}$, da CLT) não exclui o direito ao aviso prévio, na hipótese de dispensa sem justa causa ao término do ano letivo ou no curso das férias escolares.

Essa Súmula tem relação direta com o parágrafo

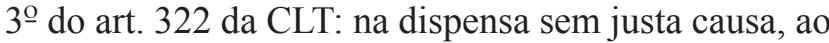
término do ano letivo ou no curso das férias escolares, é assegurado ao professor o pagamento, na mesma periodicidade contratual, da remuneração por eles percebida, na conformidade dos horários, durante o período de aulas.

Supracitado entendimento consolidado do TST e a CLT buscam inibir a dispensa que tenta atacar o recebimento dos valores de férias, por isso dispõe que o professor tem direito à percepção dos salários do período de férias ${ }^{22}$.

SUM-14 CULPA RECÍPROCA (nova redação) - Res. 121/2003, DJ 19, 20 e 21.11.2003.

Reconhecida a culpa recíproca na rescisão do contrato de trabalho (art. 484 da CLT), o empregado tem direito a $50 \%$ (cinqüenta por cento) do valor do aviso prévio, do décimo terceiro salário e das férias proporcionais.

A Súmula 14 do TST, que trata da rescisão contratual em virtude de culpa recíproca, sofreu alterações para adequar-se ao art. 484 da CLT $^{23}$ : havendo culpa recíproca no ato que determinou a rescisão do contrato de trabalho, o tribunal de trabalho reduzirá a indenização à que seria devida em caso de culpa exclusiva do empregador, por metade.

A culpa recíproca ocorre quando empregado e o empregador cometem falta grave tipificadas nos artigos 482 e 483 da CLT ${ }^{24}$.

Com a nova redação prevaleceu a tese de interpretação ampliativa. Assim, no caso de culpa recíproca há direito à metade do aviso prévio, férias, 13ํㅗㄴ salário e $20 \%$ (e não 40\%) do saldo da conta vinculada do FGTS 
SUM-46 ACIDENTE DE TRABALHO (mantida) - Res. 121/2003, DJ 19, 20 e 21.11.2003.

As faltas ou ausências decorrentes de acidente do trabalho não são consideradas para os efeitos de duração de férias e cálculo da gratificação natalina.

A Súmula 46 do TST tem relação direta com a Súmula 198 do STF (de 13/12/1963). Essa jurisprudência do Supremo Tribunal afirma que as ausências motivadas por acidente do trabalho não são descontáveis do período aquisitivo das férias.

$\mathrm{O}$ acidente do trabalho provoca a parada compulsória da atividade laboral por impossibilidade absoluta do trabalhador. Se apesar do infortúnio do obreiro se considerassem as faltas para abater os dias de férias e $13^{\circ}$ salário seria legalizar-se o "bis in idem", eternizando injustiças ${ }^{25}$.

O art. 131, III da CLT destaca que não serão consideradas faltas ao serviço as ausências decorrentes de acidente de trabalho ou enfermidade atestada pelo INSS, salvo se o empregado tiver percebido auxíliodoença ou prestação de acidente de trabalho durante 6 meses, mesmo que descontínuos.

Por fim, o entendimento do TST protege o trabalhador que sofreu acidente de trabalho (fatalidade durante trabalho ou no seu percurso), englobando também a doença profissional (patologia gerada ou agravada pelo trabalho). $\mathrm{O}$ obreiro não pode ser prejudicado com o acidente, a doença, a perda das férias e da gratificação natalina, pois seria caso de situação desproporcional, espécie de penalidade àquele que não teve culpa pela situação vivenciada ${ }^{26}$.

SUM-81 FÉRIAS (mantida) - Res. 121/2003, DJ 19, 20 e 21.11.2003.

Os dias de férias gozados após o periodo legal de concessão deverão ser remunerados em dobro.

Para análise da Súmula 81 do TST pode-se resgatar o já exposto na Súmula 7 do mesmo Tribunal e, além disso, articular com o expresso nos artigos 134 e 137, ambos da CLT.

Conforme o art. 134 da CLT, as férias devem ser concedidas ao empregado pelo empregador, em regra, em um só período, nos 12 meses subsequentes à data em que o empregado tiver adquirido o referido direito. E, conforme o art. 137 da CLT sempre que as férias forem concedidas após o prazo indicado no art. 134, o empregador deverá pagar em dobro essa remuneração.

Desse modo, o gozo do direito de férias é medida de ordem pública. O empregador, em regra ${ }^{27}$, pode determinar o momento da sua concessão (CLT, 136), mas não barrar o seu exercício, pois trata-se de direito indisponível do obreiro ${ }^{28}$. Todos os dias de férias gozados após o período legal devem ser remunerados em dobro, mesmo que o início tenha ocorrido dentro do prazo legal ${ }^{29}$. A não concessão das férias (por atraso ou venda) atenta contra a sua finalidade medicinal, pois o período de descanso também serve para eliminar as toxinas acumuladas durante o período de um ou mais anos de trabalho. O trabalho contínuo, sem períodos de férias (que são um complemento ao descanso semanal remunerado), gera danos ao organismo do trabalhador ${ }^{30}$. Além disso, há finalidade psicológica desse direito, pois viabiliza ao trabalhador mais tempo de contato com entes queridos ${ }^{31}$.

SUM-89 FALTA AO SERVIÇO (mantida) - Res. 121/2003, DJ 19, 20 e 21.11.2003.

Se as faltas já são justificadas pela lei, consideramse como ausências legais e não serão descontadas para o cálculo do período de férias.

A Súmula 89 tem relação com a Súmula 46 e com o art. 131 CLT, pois trata da hipótese das faltas justificadas, que são aquelas justificadas por lei e pelo empregador via atestados de saúde. Todavia, nada impede que se justifiquem outras faltas, desde que o empregador mostre-se convencido dos motivos apresentados pelo seu empregado. Se o empregador faz o pagamento do salário, sem desconto, desaparecem os efeitos dos possíveis abatimentos no computo das férias ${ }^{32}$.

SUM-149 TAREFEIRO. FÉRIAS (mantida) - Res. 121/ 2003, DJ 19, 20 e 21.11.2003.

A remuneração das férias do tarefeiro deve ser calculada com base na média da produção do período aquisitivo, aplicando-se-lhe a tarifa da data da concessão (ex-Prejulgado $n^{\circ}$ 22).

A Súmula 149 do TST trata de tema previsto no art. $142, \S 2^{\circ}$ da CLT: quando o salário for pago por tarefa tomar-se-á por base a media da produção no período aquisitivo do direito a férias, aplicando-se o valor da remuneração da tarefa na data da concessão das férias.

O tarefeiro é a espécie de trabalhador que recebe por tarefa e não por tempo de serviço ou produção ${ }^{33}$. Seu salário é pago com base na sua produção, mas quando cumpre a tarefa do dia pode ganhar acréscimos ${ }^{34}$.

Em resumo, o trabalhador não pode receber, no momento do gozo de suas férias, valor inferior ao que receberia se trabalhando estivesse (independente do modo de remuneração: tarefa, tempo de serviço ou pro- 
dução) e no caso específico do tarefeiro avalia-se a média produzida durante o período aquisitivo, levando-se em consideração o valor da tarifa no momento da concessão das férias ${ }^{35}$.

SUM-171 FÉRIAS PROPORCIONAIS. CONTRATO DE TRABALHO. EXTINÇÃO (republicada em razão de erro material no registro da referência legislativa) DJ 05.05.2004.

Salvo na hipótese de dispensa do empregado por justa causa, a extinção do contrato de trabalho sujeita o empregador ao pagamento da remuneração das férias proporcionais, ainda que incompleto o periodo aquisitivo de 12 (doze) meses (art. 147 da CLT) (ex-Prejulgado no 51).

Em dissonância com a Convenção no 132 da OIT, o verbete faz a ressalva taxativa de excluir dos empregados demitidos por justa causa o direito à remuneração de férias proporcionais (incompleto o período aquisitivo de 12 meses). Também nesse sentido vai o parágrafo único do artigo 146 da CLT que, expressamente, diz que na cessação do contrato de trabalho, após 12 meses de serviço, o empregado, desde que não haja sido demitido por justa causa, terá direito à remuneração relativa ao período incompleto de férias na proporção de $1 / 12$ por mês de serviço ou fração superior a 14 dias $^{36}$.

Assim, na rescisão do contrato de trabalho antes de completo o período aquisitivo em regra serão devidas férias proporcionais (remuneradas com o acréscimo de $1 / 3$ ). Na rescisão por justa causa são indevidas as férias proporcionais, aviso prévio, $13^{\circ}$ proporcional e $40 \%$ do FGTS.

Dessa forma, descabe direito ao pagamento de férias proporcionais nos casos de justa causa.

SUM-261 FÉRIAS PROPORCIONAIS. PEDIDO DE DEMISSÃO. CONTRATO VIGENTE HÁ MENOS DE UM ANO (nova redação) - Res. 121/2003, DJ 19, 20 e 21.11.2003.

O empregado que se demite antes de complementar 12 (doze) meses de serviço tem direito a férias proporcionais.

A presente Súmula, após sofrer alteração, passou a ter nova redação em 2003 e ter consonância com o expresso no art. 147 da CLT: o empregado despedido sem justa causa ou que tenha contrato extinto por prazo predeterminado, antes de completar 12 meses de serviço, tem direito à remuneração do período incompleto de suas férias laborais.

A Súmula demonstra que as férias proporcionais não são recebidas no caso de demissão por justa causa. Nas demais rescisões, sem justa causa, indireta ou pedido de demissão, serão devidos os valores correspondentes às férias, de acordo com o prazo do extinto contrato de trabalho (cada período superior a 14 dias dá ao empregado o direito a $1 / 12$ de férias proporcionais). Destaca-se que em qualquer caso de férias (proporcionais, integrais/simples ou em dobro), também será devido o adicional de 1/3 (CF/1988, art. $7^{\circ}$, XVII) ${ }^{37}$.

SUM-328 FÉRIAS. TERÇO CONSTITUCIONAL (mantida) - Res. 121/2003, DJ 19, 20 e 21.11.2003.

O pagamento das férias, integrais ou proporcionais, gozadas ou não, na vigência da CF/1988, sujeita-se ao acréscimo do terço previsto no respectivo art. $7^{\circ}$, XVII.

A Súmula 328 do TST trata de tornar mais clara e objetiva a precária redação do art. $7^{\circ}$, XVII da $\mathrm{CF} / 88^{38}$. $\mathrm{O}$ verbete busca permitir a aplicação do adicional constitucional de $1 / 3$ a todas às férias sejam elas integrais, proporcionais, vencidas, indenizadas.

Assim, o Tribunal buscou barrar as tentativas de exclusão do adicional sobre o direito das férias. Por exemplo, dispensa de empregado antes de completar o período aquisitivo para evitar o pagamento do $1 / 3$.

Desse modo, conforme o entendimento do TST, o terço constitucional de férias é devido em qualquer tipo de férias (proporcionais, integrais/simples ou em dobro). Tenha o empregado menos ou mais de um ano no emprego, o acréscimo de $1 / 3$ na remuneração das férias será devido. Não há qualquer exceção à regra ${ }^{39}$.

SUM-450 FÉRIAS. GOZO NA ÉPOCA PRÓPRIA. PAGAMENTO FORA DO PRAZO. DOBRA DEVIDA. ARTS. 137 E 145 DA CLT (conversão da Orientação Jurisprudencial no 386 da SBDI-1).

$\dot{E}$ devido o pagamento em dobro da remuneração de férias, incluído o terço constitucional, com base no art. 137 da CLT, quando, ainda que gozadas na época própria, o empregador tenha descumprido o prazo previsto no art. 145 do mesmo diploma legal.

Essa Súmula do TST decorre da conversão da OJ 386 da SDI-1 do TST. De acordo com o artigo 137 da CLT, se as férias são concedidas fora do período concessivo (total ou parcialmente fora dos 12 meses após o período aquisitivo), é obrigado ao empregador pagar a dobra do valor das férias, mesmo se apenas o pagamento ocorreu no período posterior.

Assim, a Súmula 450 pacificou a inclusão da dobra e do terço constitucional no caso das férias com pagamento fora do prazo legal. 
OJ-SDI1-195 FÉRIAS INDENIZADAS. FGTS. NÃOINCIDÊECIA (inserido dispositivo) - DJ 20.04.2005.

Não incide a contribuição para o FGTS sobre as férias indenizadas.

Essa OJ, de certa forma, prestigia o comportamento negativo do empregador, que não concede férias no período legal e ainda tem a vantagem de não contribuir para o FGTS quando for pagar as férias indenizadas. Apesar de atentar contra a lógica formal ${ }^{40}$, segue em vigor no sistema jurídico brasileiro.

OJ-SDI1-386 FÉRIAS. GOZO NA ÉPOCA PRÓPRIA. PAGAMENTO FORA DO PRAZO. DOBRA DEVIDA. ARTS. 137 E 145 DA CLT (DEJT divulgado em 09, 10 e 11.06.2010).

É devido o pagamento em dobro da remuneração de férias, incluído o terço constitucional, com base no art. 137 da CLT, quando, ainda que gozadas na época própria, o empregador tenha descumprido o prazo previsto no art. 145 do mesmo diploma legal.

A OJ 386, convertida na Súmula 450 do TST, afirma que o pagamento dobrado das férias não se dá apenas pela sua concessão fora do período concessivo. Também aplica o pagamento duplicado quando a remuneração das férias ocorre fora do prazo legal de no máximo dois dias antes do início do respectivo período.

Assim, mesmo que o trabalhador goze a integralidade das suas férias dentro do período concessivo, se receber o pagamento das férias fora do prazo legal, também terá direito ao valor dobrado e acrescido de $1 / 3$.

OJ-SDI1-394 REPOUSO SEMANAL REMUNERADO - RSR. INTEGRAÇÃO DAS HORAS EXTRAS. NÃO REPERCUSSÃO NO CÁLCULO DAS FÉRIAS, DO DÉCIMO TERCEIRO SALARIO, DO AVISO PRÉVIO E DOS DEPÓSITOS DO FGTS (DEJT divulgado em 09, 10 e 11.06.2010).

A majoração do valor do repouso semanal remunerado, em razão da integração das horas extras habitualmente prestadas, não repercute no cálculo das férias, da gratificação natalina, do aviso prévio e do FGTS, sob pena de caracterização de "bis in idem".

A presente OJ trata da negativa dos reflexos das horas extras em RSR e, com estes, nas demais verbas. Assim, o descanso semanal remunerado não deve ser integrado às horas extraordinárias para fins de apuração dos demais reflexos ${ }^{41}$.
OJ-SDIIT-5O FÉRIAS. ABONO INSTITUÍDO POR INSTRUMENTO NORMATIVO E TERÇO CONSTITUCIONAL. SIMULTANEIDADE INVIAVEL (conversão da Orientação Jurisprudencial $n^{\mathrm{O}} 231$ da SBDI-1) - DJ 20.04.2005.

O abono de férias decorrente de instrumento normativo e o abono de 1/3 (um terço) previsto no art. 7º, XVII, da CF/1988 têm idêntica natureza jurídica, destinação e finalidade, constituindo-se "bis in idem" seu pagamento simultâneo, sendo legítimo o direito do empregador de obter compensação de valores porventura pagos. (ex-OJ $n^{\mathrm{O}} 231 \mathrm{da}$ SBDI-1 - inserida em 20.06.01).

A OJ 50 deixa explícito que pode ser aplicado apenas um tipo de abono de férias, seja ele o criado por instrumento normativo ou o constitucional (desde que não seja inferior ao limite constitucional de 1/3 - art. 7으, XVII, da CF/1988). Ambos os abonos tem mesma natureza jurídica: indenizatória. Desse modo, a sua cumulação é repetição de sanção sobre mesmo fato (bis in idem).

\section{PN-100 FÉRIAS. INÍCIO DO PERÍODO DE GOZO (positivo).}

O inicio das férias, coletivas ou individuais, não poderá coincidir com sábado, domingo, feriado ou dia de compensação de repouso semanal.

Nas férias contam-se os dias corridos, sendo feriados ou finais de semana. Todavia o início do seu gozo não pode incidir em sábado, domingo, feriado ou dia de compensação de repouso semanal ${ }^{42}$.

\section{PN-116 FÉRIAS. CANCELAMENTO OU ADIANTA- MENTO (positivo).}

Comunicado ao empregado o periodo do gozo de férias individuais ou coletivas, o empregador somente poderá cancelar ou modificar o início previsto se ocorrer necessidade imperiosa e, ainda assim, mediante o ressarcimento, ao empregado, dos prejuizos financeiros por este comprovados.

O precedente normativo 116 do TST busca evitar que o empregador crie motivos para prejudicar o início do gozo das férias do trabalhador. Assim, busca reduzir a possibilidade de desgastes à saúde do obreiro.

O PN mencionando também tenta evitar que o empregador crie situações extenuantes de programação e desprogramação imotivada de férias com o simples objetivo de fazer com que o trabalhador peça demissão ${ }^{43}$.

\section{CONSIDERAÇÕES FINAIS}

Tendo em vista o que foi abordado nessa produção, podemos dizer que férias é um dos mais comuns 
exemplos de interrupção do contrato de trabalho, além de ser o de maior tempo, podendo chegar a 30 dias consecutivos (art. 130, I, CLT) sem trabalho e com remuneração.

Assim, nas férias o empregado não presta serviços (art. 138, CLT), todavia recebe remuneração (art. 129, CLT), além de contar tempo de serviço para todos os efeitos legais $\left(\S 2^{\circ} \text {, art. 130, CLT }\right)^{44}$.

Nesse artigo também ficou explícito que as férias têm um determinado caráter higiênico ${ }^{45}$. Ou seja, apresentam uma dimensão de cuidado com a saúde do trabalhador.

Além disso, a concessão das férias pode beneficiar o empregador, pois após o quinto mês de trabalho o rendimento fica reduzido, principalmente nas atividades intelectuais ${ }^{46}$. Logo, as férias, sob certo ponto de vista, podem promover aumento de capital ao empregador.

Por fim, salientamos que as férias são direito irrenunciável, constitucional, legal e remuneráveis com o adicional mínimo de $1 / 3$, sem exceção. A sua não concessão acarreta direito a uma indenização correspondente ao dobro dos valores das férias, podendo ser aplicado, conforme o caso, dano moral e existencial, pois a não concessão de férias, mesmo que parcialmente, pode configurar o dano existencial, pois conduz à obstrução a integração do trabalhador à sociedade, violando o direito da personalidade ${ }^{47}$.

\section{REFERÊNCIAS}

CESARINO JÚNIOR, Antonio Ferreira. Direito social. São Paulo, LTr, 1980.
GIGLIO, Wagner. Fundamentos e natureza jurídica das férias do trabalhador. São Paulo: Unidas, 1976.

GÓES, Maurício de Carvalho. A equiparação salarial como instrumento garantidor da isonomia nos contratos de emprego. Porto Alegre: Verbo Jurídico, 2009. 167 p.

GOTTSCHALK, Elson Guimarães. Férias anuais remuneradas. São Paulo: Max Limonad, 1956.

KLIPPEL, Bruno. Direito sumular esquematizado - TST. São Paulo: Saraiva, 2011.

MARTINS, Sérgio Pinto. Direito do Trabalho. 28. ed. São Paulo: Atlas, 2012.

MARTINS, Sérgio Pinto. Direito do Trabalho. 29. ed. São Paulo: Atlas, 2013. $1016 \mathrm{p}$.

MORAES, Alexandre de. Direito Constitucional. 30. ed. São Paulo: Atlas, 2014. 984 p.

NASCIMENTO, Amauri Mascaro. Curso de direito do trabalho: história e teoria geral do direito do trabalho: relações individuais e coletivas do trabalho. 26. ed. São Paulo: Saraiva, 2011.

NASCIMENTO, Amauri Mascaro. Iniciação ao direito do trabalho. 33. ed. São Paulo: LTr, 2007.

OLIVEIRA, Francisco Antonio de. Comentários aos enunciados do TST. 5. ed. rev. atual. ampl. São Paulo: Revista dos Tribunais, $2001.932 \mathrm{p}$

OLIVEIRA, Francisco Antonio de. Comentários aos precedentes normativos e às orientações jurisprudenciais do TST. 2. ed. rev. atual. ampl. São Paulo: Revista dos Tribunais, 2004. $633 \mathrm{p}$.

STÜRMER, Gilberto. O trabalho, o direito do trabalho e o Protocolo de San Salvador. In: Revista de Estudos Constitucionais, Hermenêutica e Teoria do Direito (RECHTD), São Leopoldo, v. 6, n. 1, p. 104-110, jan.-jun. 2014.

SÜSSEKIND, Arnaldo. Comentários à nova Lei de Férias. São Paulo: LTr, 1977.

TRIBUNAL SUPERIOR DO TRABALHO. Jurisprudência do TST. Brasília, DF. Disponível em: <http://www.tst.jus.br/ jurisprudencia $>$. Acesso em: 04 set. 2014.

\section{NOTAS}

${ }^{1}$ GÓES, Maurício de Carvalho. A equiparação salarial como instrumento garantidor da isonomia nos contratos de emprego. Porto Alegre: Verbo Jurídico, 2009, p. 21.

2 BRESCIANI, M. Stella M. Londres e Paris no Século XIX: O Espetáculo da Pobreza. São Paulo: Brasiliense, 1985. p. 25, apud GÓES, Maurício de Carvalho. A equiparação salarial como instrumento garantidor da isonomia nos contratos de emprego. Porto Alegre: Verbo Jurídico, 2009, p. 21.

3 PINTO, José Augusto Rodrigues. Curso de direito Individual do Trabalho. 2. ed. São Paulo: LTr, 1995, p. 22, apud GÓES, Maurício de Carvalho. A equiparação salarial como instrumento garantidor da isonomia nos contratos de emprego. Porto Alegre: Verbo Jurídico, 2009, p. 23.

${ }^{4}$ GOTTSCHALK, Élson. Curso de Direito do Trabalho. Rio de Janeiro: forense, 1998. p. 4, apud GÓES, Maurício de Carvalho. A equiparação salarial como instrumento garantidor da isonomia nos contratos de emprego. Porto Alegre: Verbo Jurídico, 2009. p. 23.

${ }^{5}$ GOES, Maurício de Carvalho. A equiparação salarial como instrumento garantidor da isonomia nos contratos de emprego. Porto Alegre: Verbo Jurídico, 2009. p. 29.

${ }^{6}$ MORAES, Alexandre de. Direito Constitucional. 30. ed. São Paulo: Atlas, 2014. p. 205

${ }^{7}$ Ibidem, p. 203.
${ }^{8}$ Ibidem, p. 204.

${ }^{9}$ MARTINS, Sérgio Pinto. Direito do Trabalho. 28. ed. São Paulo: Atlas, 2012, p. 591.

${ }^{10}$ KLIPPEL, Bruno. Direito sumular esquematizado - TST. São Paulo: Saraiva, 2011, p. 37

${ }^{11}$ BACHELIER, Gustavo. Les congés annuels payés. Paris, 1937, p. 4 e 5 apud NASCIMENTO, Amauri Mascaro. Curso de direito do trabalho: história e teoria geral do direito do trabalho: relações individuais e coletivas do trabalho. 26. ed. São Paulo: Saraiva, 2011.

${ }^{12}$ GOTTSCHALK, Elson Guimarães. Férias anuais remuneradas, São Paulo: Max Limonad, 1956.

${ }^{13}$ STÜRMER, Gilberto. O trabalho, o direito do trabalho e o Protocolo de San Salvador. In: Revista de Estudos Constitucionais, Hermenêtica e Teoria do Direito (RECHTD), v. 6, n. 1, p. 104-110, jan.-jun. 2014. São Leopoldo: UNISINOS. p. 108.

${ }^{14}$ MARTINS, opus citatum, p. 591.

${ }^{15}$ Ibidem, p. 627.

${ }^{16}$ SÜSSEKIND, Arnaldo. Comentários à nova Lei de Férias. São Paulo: LTr, 1977, p. 23.

${ }^{17}$ CESARINO JÚNIOR, Antonio Ferreira. Direito social. São Paulo: LTr, 1980 apud NASCIMENTO, Amauri Mascaro. Curso de direito do trabalho: história e teoria geral do direito do trabalho: relações individuais e coletivas do trabalho. 26. ed. São Paulo: Saraiva, 2011, p. 799 . 
${ }^{18}$ GIGLIO, Wagner. Fundamentos e natureza jurídica das férias do trabalhador. São Paulo: Unidas, 1976 apud NASCIMENTO, Amauri Mascaro. Curso de direito do trabalho: história e teoria geral do direito do trabalho: relações individuais e coletivas do trabalho. 26. ed. São Paulo: Saraiva, 2011, p. 799.

${ }^{19}$ NASCIMENTO, Amauri Mascaro. Curso de direito do trabalho: história e teoria geral do direito do trabalho: relações individuais e coletivas do trabalho. 26. ed. São Paulo: Saraiva, 2011, p. 799

${ }^{20}$ Ibidem, p. 799.

${ }^{21}$ KLIPPEL, Bruno. Direito sumular esquematizado - TST. São Paulo: Saraiva, 2011, p. 38.

${ }^{22}$ KLIPPEL, Bruno. Direito sumular esquematizado - TST. São Paulo: Saraiva, 2011, p. 43

${ }^{23}$ Ibidem, p. 48.

${ }^{24}$ SARAIVA, Renato. Direito do trabalho: concursos públicos. 6. ed. São Paulo: Método, 2007, p. 252.

${ }^{25}$ OLIVEIRA, Francisco Antonio de. Comentários aos enunciados do TST. 5. ed. rev. atual. ampl. São Paulo: Revista dos Tribunais, 2001. p. 137.

${ }^{26}$ KLIPPEL, Bruno. Direito sumular esquematizado - TST. São Paulo: Saraiva, 2011, p. 83

${ }^{27}$ Exemplos de exceções estão no art. $136, \S \S 1^{\mathrm{o}}$ e $2^{\mathrm{o}}-$ membros de uma família, que trabalharem no mesmo estabelecimento ou empresa, terão direito a gozar férias no mesmo período, se assim o desejarem e se disto não resultar prejuízo para o serviço. E, o empregado estudante, menor de 18 anos, tem direito a fazer coincidir suas férias laborais com as suas férias escolares.

${ }^{28}$ TRT-DF, RO 1.031/85, Des. Fernando Damasceno, Ac. 1 ${ }^{\text {a }}$ Turma, $3.191 / 86$.

${ }^{29}$ TRT 10, RO 2.416/84, Des. Libânio Cardoso, Ac. 2 ${ }^{\mathrm{a}}$ Turma, 2.309/85.

${ }^{30}$ MARTINS, Sérgio Pinto. Direito do Trabalho. 28. ed. São Paulo: Atlas, 2012. p. 311.

${ }^{31}$ OLIVEIRA, Francisco Antonio de. Comentários aos enunciados do TST. 5. ed. rev. atual. ampl. São Paulo: Revista dos Tribunais, 2001. p. 228.
${ }^{32}$ Ibidem, p. 246.

${ }^{33}$ KLIPPEL, Bruno. Direito sumular esquematizado - TST. São Paulo: Saraiva, 2011. p. 204

${ }^{34}$ NASCIMENTO, Amauri Mascaro. Iniciação ao direito do trabalho. 33. ed. São Paulo: LTr, 2007. p. 340.

${ }^{35}$ OLIVEIRA, Francisco Antonio de. Comentários aos enunciados do TST 5. ed. rev. atual. ampl. São Paulo: Revista dos Tribunais, 2001. p. 397.

${ }^{36}$ Processo: RR - 16000-53.2002.5.12.0032 Data de Julgamento: 05/05/2010, Relatora Ministra: Dora Maria da Costa, $8^{\text {a }}$ Turma, Data de Publicação: DEJT 07/05/2010.

${ }^{37}$ KLIPPEL, Bruno. Direito sumular esquematizado - TST. São Paulo: Saraiva, 2011, p. 328

${ }^{38}$ OLIVEIRA, Francisco Antonio de. Comentários aos enunciados do TST 5. ed. rev. atual. ampl. São Paulo: Revista dos Tribunais, 2001. p. 867.

${ }^{39}$ KLIPPEL, Bruno. Direito sumular esquematizado - TST. São Paulo: Saraiva, 2011, p. 412.

${ }^{40}$ OLIVEIRA, Francisco Antonio de. Comentários aos precedentes normativos e às orientações jurisprudenciais do TST. 2. ed. rev. atual. ampl. São Paulo: Revista dos Tribunais, 2004. p. 335.

${ }^{41}$ Processo: RR - 6971-80.2010.5.12.0037 Data de Julgamento: 06/08/2014, Relator Desembargador Convocado: João Pedro Silvestrin, 8 ${ }^{\underline{a}}$ Turma, Data de Publicação: DEJT 15/08/2014.

${ }^{42}$ OLIVEIRA, Francisco Antonio de. Comentários aos precedentes normativos e às orientações jurisprudenciais do TST. 2. ed. rev. atual. ampl. São Paulo: Revista dos Tribunais, 2004. p. 110.

${ }^{43}$ Ibidem, p. 122.

${ }^{44}$ MARTINS, Sérgio Pinto. Direito do Trabalho. 28. ed. São Paulo: Atlas, 2012. p. 363

${ }^{45}$ Ibidem, p. 589.

${ }^{46}$ Ibidem, p. 363.

${ }^{47}$ Processo: RR - 727-76.2011.5.24.0002. Data de Julgamento: 19/06/2013, Relator Ministro: Hugo Carlos Scheuermann, $1^{\underline{a}}$ Turma, Data de Publicação: DEJT 28/06/2013. 